\title{
Mother-Child Relationship as Perceived by Breast Cancer Women
}

\author{
Eva Mazzotti ${ }^{1 *}$, Francesco Serranò ${ }^{2}$, Claudia Sebastiani ${ }^{1}$, Paolo Marchetti ${ }^{2}$ \\ ${ }^{1}$ Divisione di Oncologia e Dermatologia Oncologica, Istituto Dermopatico dell'Immacolata-Istituto di Ricerca e \\ Cura a Carattere Scientifico (IDI-IRCCS), Rome, Italy \\ ${ }^{2}$ Facoltà di Medicina e Psicologia, Università di Roma Sapienza, Rome, Italy \\ Email: eva.mazzotti@tiscali.it
}

Received September $12^{\text {th }}$, 2012; revised October $13^{\text {th }}$, 2012; accepted November $11^{\text {th }}, 2012$

\begin{abstract}
Cancer can threat the stability of a mother's parental role, undermining her ability to take care of her children and keep the family together. We conducted face-to-face interviews to explore the experiences of mothers with breast cancer. Some mothers tend to handle their disease as if it were a temporary event. This strategy often implies a detachment from their children, in an attempt to protect them. Other strategies are instead based on the awareness that, from that moment on, the life of a mother, and that of her family, will have to go through important changes in the short and long run. The behaviors examined, adopted to safeguard children's wellbeing, can create or enhance dysfunctional and paradoxical communication strategies. The hospital staff can practically use the results of this study to help mothers successfully handle their family relationships.
\end{abstract}

Keywords: Breast Cancer; Narrative Interviews; Parenting; Qualitative Research; Mother-Children Relationship

\section{Introduction}

Parents coping with cancer generally experience high levels of distress throughout the diagnosis, treatment and prognosis process as well as a sense of guilt about the impact of the disease on their children.

In this study, we focus on the strategies that women with breast cancer adopt for involving their teenage children in the management of their illness.

The theoretical framework of the study is based on literature dealing with the impact of parental cancer on children and the family. We have turned our attention to studies of different approaches focusing on cancer, with particular regard to breast cancer.

In the last few years, many scholars have addressed these issues. Some describe the experience of parents with cancer (Elmberger et al., 2002; Helseth \& Ulfsaet, 2003, 2005; Semple $\&$ McCance, 2010), or focus in particular on the experience of women with breast cancer (Billhult \& Segesten, 2003; Öhlén \& Holm, 2006; Kaiser, 2008; Sadler-Gerhardt et al., 2010); others examine how mothers with cancer deal with the responsibilities connected with their parental role (Elmberger et al., 2005), or consider the changes in a mother's role (Fitch et al., 1999; Adams \& Dell, 2008).

Other areas of research include the communication between parents and children about maternal breast cancer (Hymovich, 1993, 1995; Barnes et al., 2000; Elmberger et al., 2000; Shands et al., 2000; Huizinga et al., 2005), the mother-child relationship (Davis Kirsch et al., 2003; Walsh et al., 2005), and the specific relationship between breast cancer survivors and their daughters (Stiffler et al., 2008).

Scholars have also explored the impact of parental cancer on children and adolescents (Lewis \& Hammond, 1996; Visser et al., 2004; Forrest et al., 2006; Osborn 2007; Schmitt et al.,

\footnotetext{
*Corresponding author.
}

2008), the case of single women with breast cancer and their relationship with children (Lewis et al., 1996), the reactions of children to the diagnosis of cancer in a parent (Patenaude, 2000; Clemmens, 2009; Kennedy \& Lloyd-Williams, 2009a; Kennedy \& Lloyd-Williams, 2009b), the markers of psychological distress in cancer patiens, spouses and children (Compas et al., 1994, 1996; Grant \& Compas, 1995; Huizinga et al., 2003; 2010; Visser et al., 2005, 2007, Edwards et al., 2008; Vannatta, 2008, 2010), and the children's anxiety related to a parent's illness (Rosenfeld et al., 1983; Rosenheim \& Reicher, 1985; Kroll et al., 1998; Nelson et al., 2002; Edwards \& Clarke, 2004; Watson et al., 2006).

In this study, we focus on how women handle their being mother over time, in relation to the cancer event. Their perception of the illness and representation of their children's needs in a particularly critical moment affect the involvement strategies they adopt to help children cope with their disease.

We examine the impact of such strategies on the motherchildren relationship, both in the short and long term. Besides, we show how certain behaviors aimed at protecting and safeguarding the wellbeing of children and of the whole family from the stressful impact of cancer are not effective and do not serve the purpose of creating and maintaining a good motherchild relationship in particularly critical circumstances.

\section{Methods}

To elicit the women's perspectives on their breast cancer experiences, we adopted a qualitative approach (Silverman, 2010), which is the most suitable method for gaining an understanding of the meanings that people assign to their experiences (Polkinghorne, 1988). We used narrative interviews to develop indepth descriptions and to obtain rich, comprehensive, detailed accounts of women's experiences.

Narrative interviews provide informants with many opportu- 
nities to select and order events themselves rather than to put events into a preordained structure.

Involving detailed examination of the participant's lifeworld, interviews make it possible to explore in detail how participants are making sense of their personal and social world (Kvale, 1996). An interview is an interpersonal situation where the relevant data are constituted by the interaction itself, in the specific situation created between the interviewer and the interviewee. Meaning is not elicited merely by apt questioning, nor simply transported through respondent replies, but is actively and communicatively assembled in the interview encounter.

\section{Participants}

After receiving approval from the Ethic Committee of the Institute, we selected participants from the patient lists of the outpatient clinic. We contacted eight Italian women, aged 26 58 years (average age 46), and all of them accepted to participate in the study. The years since their diagnoses ranged from 1 to 20. Breast cancer treatments included surgery (i.e. mastectomy, quadrantectomy, lymphadenectomy), radiation and chemotherapy, as well as various combinations of treatmens. At the time of the interview, three participants were still carrying out their work activities.

Eight women, all married at the time of the interview, had children whose average age was 15 years (range 5 - 28). Most of the children were living with their parents; others, now adults, were already living on their own.

\section{Ethical Considerations}

We approached the women during their visits to the outpatient department. We fully informed them of the objective of the study, of the interview method, and of how the collected information would be utilized. We asked all informants permission to audio record the interviews and we obtained informed written consent from them.

We informed all women of their rights to confidentiality and that confidentiality would be maintained through the omission of any personal references, and that to protect their identities all participants would be assigned pseudonyms in the interview transcript. We also told informants that their participation in the study was voluntary and withdrawal or lack of participation would not adversely influence their medical treatment. Informants received no payment for participating in the study.

\section{Procedure}

We conducted all face-to-face interviews between November 2010 and January 2011 at the hospital where women had received their cancer treatments. During the interview we asked women to share their stories of breast cancer. We encouraged each woman to reveal, in her own words, the meaning she attached to the illness and to provide insight into the impact of her illness on herself or her family. The idea was to encourage informants to speak about the issues that were pertinent to their experience of illness and to introduce ideas with which we were not already familiar.

For this purpose, the first question of our interview was open-ended ("I would like you to tell me about your experience of illness, starting from when you first found out about it...”). This kind of question not only activated a process of narrative reconstruction of women's experience, but also allowed the interviewees to talk about the issues of concern to them rather than what the researcher may have considered important, and to explore the experiences of difficulties, as well as their challenges and strategies. The participants' responses guided the direction of the interview and were followed by questions for elaboration or clarification allowing for promptings and exploration of topics raised spontaneously. Finally, a period of debriefing occurred at the end of each interview to discuss any feelings the participant might have experienced during the session.

The average length of the interviews was approximately 50 minutes.

We transcribed all interviews verbatim.

All interviews were conducted in Italian, and the excerpts included in this article were translated into English by a professional translator.

\section{Analysis}

To gain an understanding of the breast cancer experiences emerging from women's accounts, we adopted a narrative analysis approach (Riesmann, 1990, 1993, 2002; Labov, 2010). The underlying assumption of narrative research is that the construction of a story by an individual serves a purpose and is the primary way human beings make sense of their experiences. According to Riessman (1993), the task of identifying narrative segments and their representation is not a technical operation but the stuff of analysis itself; the "unpacking” of structure that is essential to interpretation. This form of interpretation is a spiral process and starts with an initial reading to gain a sense of the whole and to obtain suggestions for the next phase, the structural analysis, where the text can be explained by identifying meaningful parts and patterns.

We began the analysis with close reading and re-reading of the women's interviews so as to identify relevant parts of the interviews that could help us reconstruct each woman's story. The women's accounts were particularly meaningful because they conveyed the representations, perceptions and attitudes toward the disease that these women/mothers had at the time of the interview. Our goal was to highlight, within each story, how patients coped with the problems related to their disease in relation to their family life, and how their different conceptions of the disease, which also depended on the seriousness of their clinical condition, affected their personal and family life.

We highlighted sections on the transcripts, noting down our initial impressions about the stories and any unusual feature. In these constructed summaries we included the type of story revealed, meanings of breast cancer shared, self-identities portrayed, how women's experiences of breast cancer were situated in family life, the influence of structural factors, and the general storyline that women used to explain their experiences of breast cancer.

We also examined how the elements of the story fitted together, each storyline's sequence of events, the repetition of certain words, phrases and events, and how women transitioned from one story to another throughout the interviews.

\section{Findings}

When a woman finds out she has breast cancer, her physical and emotional stability is seriously affected. If the woman is a mother, cancer is also a real threat to the stability of her paren- 
tal role, undermining her ability to take care of her children and keep the family together. Cancer breaks in as a traumatic event, striking a woman and her whole family with all its destructive force, and producing a moment of crisis that interferes with the stability of family relationships and makes it necessary to go through an important phase of change.

Starting from the experiences reported by mothers who have survived cancer, in this article we reconstruct the history of their disease (Williams, 1984), from the moment of diagnosis on, and analyze the strategies they adopted to handle this traumatic event, with specific regard to their relationship with their young or teenage children.

Through the following excerpts taken from the women' accounts, we examine the different strategies that women adopted to handle the relationship with their children, and we point out some interesting dynamics that might be worthy of further investigation.

\section{A Personal Battle}

When a mother finds out she has breast cancer, roles and family relationships change and adapt to the reality of the disease. Depending on the seriousness of the clinical picture, and on her personal and family history, each woman experiences a series of emotions related to her situation, and develops her own conception of the disease, temporarily becoming the fulcrum around which the people who support her in the battle against cancer revolve.

\section{Excerpt 1: Clelia, 40 years \\ In that moment \\ I was actually at the centre of the world. \\ So I had to show my strength somehow, and also repay, I guess, \\ the love of the people around me, \\ so the only way was to fight, \\ but with that sort of lightness, as I said. \\ I mean, I fought so hard.}

In this excerpt, Clelia describes her experience in the days after surgery. Using a spatial metaphor, she puts herself at the centre of a network of people who are around her in the crucial moment of the traumatic event, providing her with emotional support and with the necessary strength to fight her personal battle against cancer. As we observed in our interviews, from which the present excerpt is taken, when it comes to talking about particularly critical moments related to their illness, women almost always refer to the most significant persons, the "indispensable" family members or friends who supported them in those moments. By making reference to the "indispensable" ones, to how they were there for her, showing their love and providing support, they implicitly evoke the "most notable absent players" in this phase: their children. This clear-cut attempt of Clelia to keep her children at a distance probably depends on her parental role, as if it were a way to defend her children from what she considers a grown-ups business, which only involves a close circle of people who support her in her "battle".

The non-involvement of children is also evident in the continuation of the account, where Clelia says that the first thing she did as soon as her clinical situation made it possible was to accompany her daughter on her first day of school, being pre- sent in a moment that she thought was important for her.

Excerpt 2: Clelia

After the first six rounds of chemo,

I had surgery.

On the 13th of September

I left the hospital with drainage tubes still attached.

On the 15th of September I took my daughter to school.

She was starting the 3rd year of middle school.

I mean, with no difficulties,

I mean, with drainage tubes in the pockets of my jeans...

It was perfectly normal for me.

Bald, in front of Anna's school.

And she, even she... I think I was a lesson

to my daughter, too. It meant a lot to me.

[...]

It was vital for me to come out of this story,

um, as a winner.

[...]

I mean, to tell the truth,

I've often thought about it, so...

Anna has never cried in front of me,

probably because I've never cried in front of her.

So, of course not, she's always seen a strong mother.

But then she cried at school,

because the teachers, I mean, the schoolmistresses

told me so.

The physical presence of Clelia at school, with her body visibly tried by chemotherapy and surgery, is a key episode in her account. What emerges is the particular drama of her suffering as well as the strength and the courage that Clelia attributes to herself when she participates in a situation where she can and must present herself as a winner. Her description follows a precise temporal sequence of events culminating in the identification of a specific date, which represents the most crucial moment in her battle and allows Clelia, in spite of her visible physical suffering, to present herself as a winner.

In Clelia's description of this traumatic event, we can identify a double level of analysis. Her battle against cancer has to do with her medical condition and with the drama of her physical devastation, but there is also an emotional level, where the lightness with which she confronts her "enemy" mitigates the emotional impact of the disease and apparently eases its conesquences.

The event that Clelia describes is also supposed to have an educational value for Anna, her daughter. The gesture of her mother, who is with her on her first day of school, becomes a sort of reassurance provided by the fact of being there, no matter how. While the mother emphasizes her ability to maintain a sort of normality in her life, focusing on a symbolic dimension - her being there- - her daughter probably has a different perception, giving more importance to her mother's inability to show emotional closeness, rather than to her physical presence. For Clelia it is normal to take her daughter to school in precarious health conditions, but her daughter might feel that there is nothing normal in seeing her mother bald and with drainage tubes because of a disease that she does not have the courage to share with her: a disease that has temporarily pushed her mother away from her and that makes her look disfigured, forcing her into a personal battle that does not allow her to express her feelings. 


\section{Contrasting Elements}

In the following excerpt we see a different way to handle the traumatic event. Here, the main point of concern is the selection of people to be involved and the need to keep the disease secret by controlling the information to be shared.

Excerpt 3: Livia, 42 years

I didn't tell anyone about it,

except for the closest circle of people around me.

The wig allowed me to live among the people

without being...

Actually, well, with my way of smiling,

of being nice, everybody said...

everybody always told me:

You look so good, you look so good,

but I was getting chemo, I wasn't good at all,

but even so, I tricked the tumor.

Well then, you didn't get your way! (she laughs.)

In Livia's account, the circle of people who know about her cancer is quite narrow. She doesn't involve her children. In this case, cancer becomes a personal battle that, unlike the case we examined before, consists in a silent resistance against its devastating force, which destroys her physically, but must not compromise Livia's social life. The information control and the use of the wig do not prevent Livia from smiling. However, resorting to these sorts of artificial ploys, she actually shows the weakness of her family life, where such a dramatic situation inevitably affects her children's wellbeing.

\section{Excerpt 4: Livia}

The closeness of my children who, well...

They didn't even know what a tumor

or the chemo was, they would get scared otherwise...

I told them I had...

Mum had a cyst, she had surgery.

So the doctors, to prevent it from happening again, gave me this treatment,

and I lost my hair and I suffered a lot,

but don't worry, don't worry.

Then, when they actually realized

that after four or five days I felt better,

and I started smiling and everything,

they stopped worrying...

So, their normal presence, the total normality

of their cheerfulness, their tears, their anger

when something went wrong at school,

well, normality made me... made me strong, um,

and there are also three... two or three friends of mine

who know about it and they...

Of course, they are people I've chosen myself, so...

Even in this case, the concept of normality is particularly important. Livia thinks that her two teenage children (eleven and twelve years old) are not aware of the suffering she is going through, just because they do not know the full circumstances of her disease.

This sort of communication that a mother establishes with her children in an attempt to protect them is dysfunctional: not only it does not serve the purpose of protecting the children, but it also causes chaos, feelings of guilt, and shows the limits and weaknesses of a strategy based on the involvement/non-involvement of children in a critical family environment.

\section{Excerpt 5: Livia}

Yes, I involved them and I didn't let them get scared.

I say yes, I was sick, I am sick right now,

but you know that in two or three days

I'm going to be fine.

I mean, after all it's a disease, it's a strong treatment,

but we can get over it,

I mean, I wanted them to be sure

that they could get over

the pain, the disease, the physical suffering, um...

So, when they looked at me, and they were scared,

I was always able to tell them

Don't worry,

Don't worry,

I'll be fine in a moment,

I'll be fine in a moment, um...

And then, well, I wanted them to go out.

My husband took them around in those afternoons.

They didn't stay with me 24 hours a day,

because, I mean...

I believe we have to make our children strong.

We have to...

help them relieve anxieties, as far as possible, because all of us have our own, it's inevitable...

We can't avoid that.

Maybe the anxiety and fear of... of... of-

makes you grow up in another positive way,

but, in general, they- well... they saw I was fine

and so they were fine, too,

because they trust me.

Even in this latter excerpt, the paradoxical situation described by Livia reveals the ineffectiveness of a strategy that only relies on handling the most acute stage of the problem. Her attempt to preserve an image of invulnerability and an appearance of normality despite her evident psychophysical suffering shows all its weakness.

The situation described by Livia is paradoxical because she is actually unable to control the effects of chemotherapy, and when she goes through long periods of suffering her children take care of her without even knowing what is happening to her, or why she minimizes her condition and tells them not to worry when she is actually suffering so much.

This sort of minimization, or even denial of her condition, inevitably affects the emotional relationship between mother and children in a moment when they should instead grow closer and strengthen their relationship. Liva acts as if it were possible to avoid the emotional distress associated with her disease by simply keeping information under control.

This kind of communication is also dysfunctional with regard to Livia's educational purposes: with her behavior, she thinks she can make her children understand that it is possible to get over difficulties; and she is convinced that all anxieties and fears associated with her condition can help them grow stronger and enhance their mutual trust.

In the following excerpt, a newly-diagnosed mother points out the necessity of informing her children about her condition.

Excerpt 6: Sara, 36 years

I talked with them... because, especially in those days,

I was sick,

so I had to tell them something (in Roman dialect) 
I mean... something... well, just like

some sort of warning that mum wasn't feeling well,

I think it was necessary.

I mean, they too,

just like all of us, need some time to take it in, don't they?

I mean, to... to... understand. No, not to understand,

but to enter this world in some way, right?

So they had to be warned, yes.

Assuming that a three-year-old may be warned.

So, "warned" in a manner of speaking.

As we can see from this account, before telling her children what is happening, Sara makes a personal evaluation of the situation: when she explains to them why she has to go into hospital and stay away from home to receive treatments, or when she has to justify her physical suffering to them, she takes account of their ability to understand, which depends on their age. In the following excerpt, Sara talks about how she explained her condition to her children (three and four years old).

\section{Excerpt 7: Sara}

I told them that mum had pain in her breast,

because, I mean, they saw me, they see me.

I've never been ashamed to share things with them, so...

I told them that I had this problem,

that the doctor hadn't been able to solve the problem, so I had to see some other doctor. I had to justify

that I was taking medicine, to begin with,

and that unfortunately

I couldn't be with them all the time...

It was inevitable, so...

But now, for example, I don't tell them everything.

In that critical phase

I felt I had to warn them in some way,

but now, for example,

when I go to therapy every week,

I don't say anything to them.

Every once in a while I tell them I'm going to the doctor.

Some other times I tell them I'm going out for a visit...

ehm, I have to go to some office and wait in line for...

Mum has something to see to, things like that.

I mean, they know it, but...

Sara's account has some similarities with the ones we examined before, with regard to the amount of information to be shared with children and to the modes of communication. Whenever it is not possible to do otherwise, children are provided with confused and fragmentary pieces of information about their mother's condition, which are supposed to justify her temporary absence when she goes into hospital, and her frequent absences during the treatment.

The control over the information to be shared acts as a filter that allows children to only gain a partial understanding of the problem, turning them into passive spectators with no possibility of reaction. This mode of communication has a profound impact on the emotional state of teenagers who go through a similar experience, and results in a sense of guilt and punishment, because they feel helpless in front of their mother's suffering, while their mother conceals her real state of health from them.

In the above-mentioned cases, the mothers themselves admit their communication failures and the presence of conflicting information in their relationship with children. They realize they have not been clear enough, they acknowledge their inefficiency and sometimes extend the information control to people outside the family, because they are aware that their children understand most of what they are trying to conceal. The following excerpt perfectly exemplifies this sort of attitude.

\author{
Excerpt 8: Sara \\ I actually talked with their teachers \\ and told them about the situation \\ they were going through. \\ Even if they are not fully aware of it, \\ I think they feel it, \\ also because when I take cortisone for my therapy, \\ my hair stands on end all day (she laughs), so... \\ Well, they are aware of it, \\ I mean, of course they are aware of it.
}

The mother is aware that there are situations where her system of protection does not work properly. Some treatments make it impossible for her to keep the disease secret and to remain physically unchanged. So the mother looks for emotional support in the children's places of socialization. This sort of behavior comes from her need to keep children's reactions under control, and to understand whether the pieces of information provided and the ones filtered out still make it possible for her to handle an ever-changing situation that could easily slip out of her hands, regardless of the level of protection she adopts. Our objective is not to criticize the solution adopted, but to point out that, in all likelihood, this behavior, protective as it may be, is part of a strategy aimed at giving an active role of control to other people who are close to her children. Children, although relegated to a passive role, certainly have a clear idea of their mother's disease, which is also reinforced by the elements that their mother tries to keep under control in an attempt to protect them.

\section{Responsibility}

So far we have examined a series of dysfunctional models of behavior. We now focus on a case where, instead, a mother immediately involves her children in the management of her disease, thus contributing, in the long run, to create a family situation that is closer to "normality". The following excerpt is about Romina (ten years after the diagnosis), who describes her routine check-ups and talks about the moment when she informed her youngest daughter (sixteen years old at the time of the interview) about the negative results of her medical tests:

\section{Excerpt 8: Romina, 42 years}

My daughter, the little one, recently told me, when I gave her the latest news:

Yes, mum, we are used to it by now.

And this thing made me...

Um, in a sense, I was glad about it, and not because...

Since the very first day I knew about this thing,

I did... I told it to my daughters,

even if they were little.

I felt like it was fair for them to know about it

[...]

So I thought it was better,

after talking with my husband,

to tell them about it clearly,

with a few words, a few simple words, 
because we used to talk about everything else,

I used to talk with my daughters,

so I couldn't do otherwise.

Romina's family life revolves around her periodic screening tests. In other parts of the interview, Romina says that both before the visit and after, when she was waiting for the results, she involved the whole family. Both parents have jointly adopted this involvement strategy since the diagnosis. Being used to talking with her daughters (nine and six years old at the time of the diagnosis), she informs them about her state of health with a few simple words. This choice has proved to be effective over the years, allowing Romina to face both the numerous rounds of chemotherapy and the threat of new therapeutic treatments without feeling lonely.

This involvement strategy gives an active role to all family members and, in the long run, allows the daughters to participate in the history of her mother's disease, which evolves parallel to the history of the family, also contributing to establishing a dynamic form of adaptation to the crisis. In the following excerpt, Romina talks about the normality of her family life, from the initial moment of crisis to the changes in the family roles and relationships occurred during the process of adaptation to the reality of the disease.

\author{
Excerpt 9: Romina \\ Over the years I've tried to- \\ to live my life, um, as normally as possible \\ as peacefully as possible, without... um \\ The dis-[ease], the problem shouldn't have to... \\ How can I say? \\ ...to cast a shadow over the whole family, \\ to create that sort of... of... \\ [...] \\ I think I did my best to... to keep on... um \\ (1.0) to keep them... not to make them... I don't know... \\ how- how to explain... um \\ not to make them grow up in a world... well... \\ where... it was the disease that... I mean... \\ How can I say? (in Roman dialect) \\ ...it was predominant in the house, ok? \\ So, yes, it was part of our lives, \\ but it didn’t have to take us over completely. \\ [...] \\ What my daughter told me made me think that \\ I had achieved the goal I had set for myself, \\ to just let them live their childhood \\ as peacefully as possible, until they grow up, \\ and I think I made it.
}

Romina says she is glad her daughter has got used to her disease. She believes she has achieved her goal, allowing her children to live their childhood peacefully in spite of her disease.

Romina's attitude toward the disease, the involvement of her husband and the explanations given to her children appear as a good strategy to handle cancer. This strategy is not limited to the acute stage of the disease, but involves the whole family in a wider perspective, also attributing an active role to children.

\section{Discussion}

The stories we have examined so far show different ways to handle the crisis arising after a breast cancer diagnosis. When diagnosed with cancer, patients seem to focus on how to handle the temporary moment of emergency. They often forget that, from that moment on, their life, and the life of their family, will have to go through significant, long-term changes. The desire to protect their children from suffering and to preserve their role as mothers, in a moment when their vulnerability is evident and the "normality" of the family is compromised, is not always consistent with the behaviors performed to achieve such goal.

These stories show that, when cancer breaks in a woman's/mother's life, emotions related to fear, to death, and sometimes to the expectations for the outcomes of surgery, can affect her perception of reality, leading her to only focus on how to handle an emergency situation, instead of developing an overall strategy able to take account of the problems arising immediately after the diagnosis. Even if the quality of a woman's life after the treatment certainly depends on her physical ability to withstand pain and exhaustion and on the seriousness of the clinical picture, when diagnosed with cancer, a woman probably does not realize that she will have to go through cyclical treatments and periodical check-ups, which can be painful and eventually compromise the relationship with her children. When a woman only focuses on how to handle an emergency situation, i.e. on the acute stage of the disease, children can become a problem to be handled, too. In the long run, the lack of projection into the future, the inability to foresee the changes brought about by the disease, can affect the ability to handle the crisis and meet the needs of the family, of children in particular. In these cases, the behaviors that a woman engages in to temporarily safeguard children's wellbeing can create or enhance dysfunctional and paradoxical communication strategies, especially when the personal and family situation is already problematic. In other cases, these behaviors make it more difficult to handle a situation of chronic disease, which evolves parallel to the family life.

This tendency to only focus on the immediate future probably also depends on how doctors communicate prognostic information to their patients. Unlike their colleagues from other countries, Italian doctors tend not to provide enough information about the long-term development of treatments or the actual possibilities of recovery.

Whatever the clinical course, gaining an insight into the future development of the disease could contribute to building solid family relationships based on mutual trust and concreteness. A strategy aimed at involving all family members and giving them an active role is not based on a protective detachment, but on the emotional closeness of family members. An emotional relationship based on mutual trust and transparency also allows children, depending on their age, to have a clear idea of what is really happening to their family. This way, children are not a problem to be handled, but individuals able to co-handle the problem.

\section{Conclusion}

Through women's accounts, this study shows the process of change in women's identity triggered by the onset of the disease, which inevitably affects their life and the lives of their children.

Some mothers tend to handle their disease as if it were a temporary event. This strategy often implies a sort of detachment from their children, in an attempt to protect them. Other strategies are instead based on the awareness that, from that 
moment on, their life, and the life of the whole family, will have to go through important changes in the short and long run.

Although our findings are not statistically representative compared to many others focusing on this theme, being only significant in relation to the personal history of each individual, they however help identify typical situations occurring when a mother is diagnosed with breast cancer. For the sake of intellectual honesty and methodological rigor, we cannot extend the results of our analysis beyond the single stories collected and partially reported, but we have nevertheless been able to highlight representations, perceptions, emotional states and attitudes associated with the onset of cancer, which are probably common to most of the people who experience similar events.

Our findings could be relevant for the hospital staff members (doctors, nurses, psychologists, patient associations, etc.) who are responsible for providing clear and detailed information on surgical procedures and on the long-term development of treatments. We suggest that the medical staff enhance their communication skills to better address the emotional needs that might require further psychological support and to conesquently improve the psychosocial wellbeing of the persons involved.

In this perspective, nurses play a particularly significant role, having more easily access to the patient's experience and family life. Acting as intermediaries between doctors, patients and families, they could identify any problematic situation and promote suitable intervention strategies.

One last suggestion concerns patient associations, which often operate parallel to hospitals and are therefore an important source of support. It would be advisable for them to involve specialized personnel staff able to provide adequate support and assistance to families both in the short and long run.

As for further research perspectives, it would be interesting to examine the cases of hereditary neoplasia and analyze the relationships between parents and children in such circumstances. It would also be interesting to collect stories of women with grown-up children and consider the perspective of children and fathers/husbands. Finally, given that this study was conducted in Italy,it would be interesting to further examine these issues by analyzing cultural similarities and differences in other countries.

\section{Acknowledgements}

We thank all the women who have dedicated their time to this study.

\section{Declaration of Conflicting Interests}

The authors declared no potential conflicts of interest with respect to the research, authorship, and/or publication of this article.

\section{Funding}

The authors received no financial support for the research, authorship, and/or publication of this article.

\section{REFERENCES}

Adams, E., \& Dell, P. (2008). Being a good mother: A discourse analysis of women's experiences of breast cancer and motherhood. Psy- chology of Women Section Review, 10, 3-12.

Barnes, J., Kroll, L., Bruke, O., Lee, J., Jones, A., \& Stein, A. (2000). Qualitative interview study of communication between parents and children about maternal breast cancer. British Medical Journal, 321, 479-482. doi:10.1136/bmj.321.7259.479

Billhult, A., \& Segesten, K. (2003). Strength of motherhood: Nonrecurrent breast cancer as experienced by mothers with dependent children. Scandinavian Journal of Caring Sciences, 17, 122-128. doi:10.1046/j.1471-6712.2003.00219.x

Clemmens, D. A. (2009). The significance of motherhood for adolescents whose mothers have breast cancer. Oncology Nursing Forum, 36, 571-577. doi:10.1188/09.ONF.571-577

Compas, B. E., Worsham, N. L., Epping-Jordan, J. E., Grant, K. E., Mireault, G., Howell, D. C., et al. (1994). When mom or dad has cancer: markers of psychological distress in cancer patients, spouses, and children. Health Psychology, 13, 507-515. doi:10.1037/0278-6133.13.6.507

Compas, B. E., Worsham, N. L., Ey, S., \& Howell, D. C. (1996). When mom or dad has cancer: II. Coping, cognitive appraisals, and psychological distress in children of cancer patients. Health Psychology, 15, 167-175. doi:10.1037/0278-6133.15.3.167

Davis Kirsch, S. E., Brandt, P. A., \& Lewis, F. M. (2003). Making the most of the moment: when a child's mother has breast cancer. Cancer Nursing, 26, 47-54. doi:10.1097/00002820-200302000-00007

Edwards, B., \& Clarke, V. (2004). The psychological impact of a cancer diagnosis on families: The influence of family functioning and patients' illness characteristics on depression and anxiety. PsychoOncology, 13, 562-576. doi:10.1002/pon.773

Edwards, L., Watson, M., St. James-Roberts, I., Ashley, S., Tilney, C., Brougham, B., et al. (2008). Adolescent's stress responses and psychological functioning when a parent has early breast cancer. Psycho-Oncology, 17, 1039-1047. doi:10.1002/pon.1323

Elmberger, E., Bolund, C., \& Lützen, K. (2000). Transforming the exhausting to energizing process of being a good parent in the face of cancer. Health Care for Women International, 21, 485-499. doi:10.1080/07399330050130287

Elmberger, E., Bolund, C., \& Lützen, K. (2002). Men with cancer. Changes in attempts to master the self-image as a man and as a parent. Cancer Nursing, 25, 477-485.

doi:10.1097/00002820-200212000-00013

Elmberger, E., Bolund, C., \& Lützen, K. (2005). Experience of dealing with moral responsibility as a mother with cancer. Nursing Ethics, 12, 253-262. doi:10.1191/0969733005ne787oa

Fitch, M. I., Bunston, T., \& Elliot, M. (1999). When mom's sick: Changes in a mother's role and in the family after her diagnosis of cancer. Cancer Nursing, 22, 58-63. doi:10.1097/00002820-199902000-00011

Forrest, G., Plumb, C., Ziebland, S., \& Stein, A. (2006). Breast cancer in the family-Children's perceptions of their mother's cancer and it's initial treatment: qualitative study. British Medical Journal, 332, 998-1003. doi:10.1136/bmj.38793.567801.AE

Grant, K. E., \& Compas, B. E. (1995). Stress and anxious-depressed symptoms among adolescents: Searching for mechanisms of risk. Journal of Consulting \& Clinical Psychology, 63, 1015-1021. doi:10.1037/0022-006X.63.6.1015

Helseth, S., \& Ulfsæt, N. (2003). Having a parent with cancer; Coping and quality of life of children during a period of serious illness in the family. Cancer Nursing, 26, 337-344. doi:10.1097/00002820-200310000-00003

Helseth, S., \& Ulfsæt, N. (2005). Parenting experiences during cancer. Journal of Advanced Nursing, 52, 38-46. doi:10.1111/j.1365-2648.2005.03562.x

Huizinga, G. A., van der Graaf, W. T., Visser, A., Dijkstra, J. S., \& Hoekstra-Weebers, J. E. (2003). Psychosocial consequences for children of a parent with cancer: a pilot study. Cancer Nursing, 26, 195-202. doi:10.1097/00002820-200306000-00004

Huizinga, G. A., Visser, A., van der Graaf, W. T., Hoekstra, H. J., Gazendam-Donofrio, S. M., \& Hoekstra-Weebers, J. E. (2010). Stress response symptoms in adolescents during the first year after a parent's cancer diagnosis. Supportive Care in Cancer, 18, 1421-1428. doi:10.1007/s00520-009-0764-6 
Huizinga, G. A., Visser, A., van der Graaf, W. T., Hoekstra, H. J., \& Hoekstra-Weebers, J. E. (2005). The quality of communication between parents and adolescent children in the case of parental cancer. Annals of Oncology, 16, 1956-1961. doi:10.1093/annonc/mdi395

Hymovich, D. P. (1993). Child-rearing concerns of parents with cancer. Oncology Nursing Forum, 20, 1355-1360.

Hymovich, D. P. (1995). The meaning of cancer to children. Seminars in Oncology Nursing, 11, 51-58. doi:10.1016/S0749-2081(95)80043-3

Kaiser, K. (2008). The meaning of the survivor identity for women with breast cancer. Social Science \& Medicine, 67, 79-87. doi:10.1016/j.socscimed.2008.03.036

Kennedy, V. L., \& Lloyd-Williams, M. (2009a). How children cope when a parent has advanced cancer. Psycho-Oncology, 18, 886-892. doi:10.1002/pon.1455

Kennedy, V. L., \& Lloyd-Williams, M. (2009b). Information and communication when a parent has advanced cancer. Journal of Affective Disorders, 114, 149-155. doi:10.1016/j.jad.2008.06.022

Kroll, L., Barnes, J., Jones, A. L., \& Stein, A. (1998). Cancer in parents: Telling children. British Medical Journal, 316, 880. doi:10.1136/bmj.316.7135.880

Kvale, S. (1996). Interviews: An introduction to qualitative research interviewing. Thousand Oaks, CA: SAGE Publishings, Inc.

Labov, W. (2010). Narratives of personal experience. In P. Hogan (Ed.), Cambridge Encyclopedia of the Language Sciences. Cambridge: Cambridge University Press.

Lewis, F. M., \& Hammond, M. A. (1996). The father's, mother's, and adolescent's functioning with breast cancer. Family Relations, 45, 456-465. doi:10.2307/585176

Lewis, F. M., Zahlis, E. H., Shands, M. E., Sinsheimer, J. A., \& Hammond, M. A. (1996). The functioning of single women with breast cancer and their school-aged children. Cancer Practice, 4, 15-24.

Nelson, E., \& While, D. (2002). Children's adjustment during the first year of a parent's cancer diagnosis. Journal of Psychosocial Oncology, 20, 15-36. doi:10.1300/J077v20n01_02

Öhlén, J., \& Holm, A. K. (2006). Transforming desolation into consolation: Being a mother with life-threatening breast cancer. Health Care for Women International, 27, 18-44. doi:10.1080/07399330500377226

Osborn, T. (2007). The psychosocial impact of parental cancer on children and adolescents: A systematic review. Psycho-Oncology, 16, 101-126. doi:10.1002/pon.1113

Patenaude, A. F. (2000). A different normal: reactions of children and adolescents to the diagnosis of cancer in a parent. In L. Baider, C. L. Cooper, \& A. K. De-Nour (Eds.), Cancer and the Family (2nd ed., pp. 239-253). Chichester: John Wiley and Sons.

Polkinghorne, D. E. (1988). Narrative knowing and the human sciences. State University of Albany: New York Press.

Riessman, C. K. (1990). Strategic uses of narrative in the presentation of self and illness: A research note. Social Science and Medicine, 30, 1195-200. doi:10.1016/0277-9536(90)90259-U

Riessman, C. K. (1993). Narrative analysis. Newbury Park, CA: SAGE Publishings, Inc.

Riessman, C. K. (2002). Analysis of personal narratives. In J. D. Gubrium, \& J. A. Holstein (Eds.), Handbook of interview research: Context and method (pp. 695-710). Thousand Oaks, CA: SAGE Publishings, Inc.

Rosenfeld, A., Caplan, G., Yaroslavsky, A., Jacobowitz, J., Yuval, Y.,
\& LeBow, H. (1983). Adaptation of children of parents suffering from cancer: A preliminary study of a new field for primary prevention research. Journal of Primary Prevention, 3, 244-250. doi:10.1007/BF01325407

Rosenheim, E., \& Reicher, R. (1985). Informing children about a parent's terminal illness. Journal of Child Psychology and Psychiatry, 26, 995-998. doi:10.1111/j.1469-7610.1985.tb00613.x

Sadler-Gerhardt, C. J., Reynolds, C. A., Britton, P. J., \& Kruse, S. D. (2010). Women breast cancer survivors: Stories of change and meaning. Journal of Mental Health Counseling, 32, 265-282.

Schmitt, F., Piha, J., Helenius, H., Baldus, C., Kienbacher, C., Steck, B., et al. (2008). Multinational study of cancer patients and their children: Factors associated with family functioning. Journal of Clinical Oncology, 26, 5877-5883. doi:10.1200/JCO.2007.12.8132

Semple, C. J., \& McCance, T. (2010). Parents experience of cancer who have young children: A literature review. Cancer Nursing, 33, 110-118. doi:10.1097/NCC.0b013e3181c024bb

Shands, M. E., Lewis, F. M., \& Zahlis, E. H. (2000). Mother and child interactions about the mother's breast cancer: An interview study. Oncology Nursing Forum, 27, 77-85.

Silverman, D. (2010). Doing Qualitative Research: A practical handbook (3rd ed.) London: SAGE Publishings, Inc.

Stiffler, D., Barada, B., Hosei, B., \& Haase, J. (2008). When mom has breast cancer: Adolescent daughters' experiences of being parented. Oncology Nursing Forum, 35, 933-940.

doi:10.1188/08.ONF.933-940

Vannatta, K., Grollman, J. A., Noll, R. B., \& Gerhardt, C. A. (2008). Impact of maternal breast cancer on the peer interactions of children at school. Psycho-Oncology, 17, 252-259. doi:10.1002/pon.1232

Vannatta, K., Ramsey, R. R., Noll, R. B., \& Gerhardt, C. A. (2010). Associations of child adjustment with parent and family functioning: comparison of families of women with and without breast cancer. Journal of Development and Behavioral Pediatries, 31, 9-16. doi:10.1097/DBP.0b013e3181c82a44

Visser, A., Huizinga, G. A., Hoekstra, H. J., van der Graaf, W. T., Gazendam-Donofrio, S. M., \& Hoekstra-Weebers, J. E. (2007). Emotional and behavioral problems in children of parents recently diagnosed with cancer: A longitudinal study. Acta Oncologica, 46, 67-76. doi:10.1080/02841860600949560

Visser, A., Huizinga, G. A., Hoekstra, H. J., van der Graaf, W. T., Klip, E. C., Pras, E., et al. (2005). Emotional and behavioural functioning of children of a parent diagnosed with cancer: A cross-informant perspective. Psycho-Oncology, 14, 746-758. doi:10.1002/pon.902

Visser, A., Huizinga, G. A., van der Graaf, W. T., Hoekstra, H. J., \& Hoekstra-Weebers, J. E. (2004). The impact of parental cancer on children and the family: A review of the literature. Cancer Treatment Reviews, 30, 683-694. doi:10.1016/j.ctrv.2004.06.001

Walsh, S. R., Manuel, J. C., \& Avis, N. E. (2005). The impact of breast cancer on younger women's relationships with their partner and children. Families, Systems and Health, 23, 80-93. doi:10.1037/1091-7527.23.1.80

Watson, M., St. James-Roberts, I., Ashley, S., Tilney, C., Brougham, B., Edwards, L., et al. (2006). Factors associated with emotional and behavioural problems among school age children of breast cancer patients. British Journal of Cancer, 94, 43-50. doi:10.1038/sj.bjc.6602887

Williams, G. (1984). The genesis of chronic illness: Narrative reconstruction. Sociology of Health \& Illness, 6, 175-200. doi:10.1111/1467-9566.ep10778250 